\title{
Religion in Secularized and Post-Secularized Europe
}

\author{
Monica Martinelli
}

\section{1 \\ Introduction: the Frame of Reference}

Viewed by anyone wondering about the role of religion in Europe today, the phenomenon of migration cannot fail to arouse a certain degree of interest.

In the second half of the 1900s, when an extensive literature announced the imminent end of the religious phenomenon, in Europe -as in other parts of the world- a different scenario continued to unfold: a religiosity certainly in crisis, increasingly relegated to the personal sphere and detached from institutional structures, reinvented in its content and influenced by some factors of secularization, but nevertheless present. In many cases the presence of religion, especially in its more traditional and collective forms, takes on significant characteristics precisely in relation to the migration phenomenon, since for many immigrants belonging to a religion is by no means a secondary dimension of their identity.

In itself, the European scenario is a composite, plural one, which cannot be explained simply by choosing between two options: "secularization" versus "non-secularization". It is a much more articulated, complex phenomenon, certainly geographically and nationally but, more in general, for the vitality of the religious phenomenon and of the individual forms that it adopts: elements that are the result of a continuous intersection of long processes and secularizing influences as well as of responses reacting to those processes and those influences - not without new dilemmas and conflicts.

What seems evident is that we are living in a different epoch from the one defined as completely secularized. In it, new challenges are emerging; indeed, if we are not convinced of a definitive disappearance of religion, we cannot ignore the possibility that the process of moving away from religious practices and the mistrust or even neglect of the contents of faith can progressively intensify. The end-point of this process is no longer only atheism as a strong position taken up towards faith, but concerns all the alternative forms to believing 
which qualify our times, ranging from interpretations of agnosticism and laicism, which express a certain indifference towards questions of faith, to new forms of spirituality, up to the emergence of a fluctuating religiosity, often completely modelled and withdrawn into the subject, but sometimes maintaining some reference to a traditional religion in the background. In this panorama, however, we also find the more traditional expressions of the religious experience, connected with historic Churches or new groups, along with the emergence of the phenomenon of religious radicalization, which takes the form of fundamentalism in its multi-faceted expressions.

In the varied and stratified religious composition of society described as "post-secular", new problems open up as do new opportunities for renewal for the religions themselves; the religious meaning continues to be spread, even if with profoundly different demands and according to profoundly different modes from the past.

In the present chapter we shall dwell first of all on the debate about secularization, taking up its salient features: it developed, as is known, mainly in a western context and received a strong impulse from the European sociologists of the late 1800 s and early 190os. A polysemic concept, the term "secularization" has lent itself to many different interpretations with the risk of not capturing important nuances of reality, especially where its use has claimed to entirely represent an epoch, according to a subtractive view of history. From this point of view, the change in outlook within that debate provides an important passage to understanding more about the complexity of western society and of individual life in terms of religious experience.

After tracing the main lines of this debate, we shall pinpoint some processes concerning religion within the context of post-secular society: alongside the insistent secularization a more composite, not easily defined picture emerges where, on the one hand, religion is closely connected with cultural and social transformations within the European countries, but on the other hand becomes the borderline where contradictory pressures and, in some cases, thorny questions relating to the coexistence between people with different religious traditions interweave. These questions, well beyond the religious contents in the strict sense, threaten to bring about the collapse of these very contents onto problems of another kind, which would need to be treated differently.

Finally, we shall try, within the cross pressures to which the religious experience is subjected and from which it takes shape in post-secular society, to highlight the challenge of pluralism and the role of religion within our time, also in relation to migratory phenomena. 


\subsection{The "Prophecies" of the Classics of Sociology}

In the debate that opened up in the social sciences, the long-dominant theses of secularization argued that a progressive advancement of modernity would inevitably be followed by a decline in the religious phenomenon, which would eventually disappear altogether. This religious eclipse was supposed to involve a progressive retreat of religion from the public sphere and social life and the exclusion of the dimension of transcendence from the domain of the personal conduct of life (Ferrara, 2009). In other words, secularization would be followed by a single possible effect: the transformation of religion, following the processes linked to modernity, would coincide with the end of the religious experience, both in the forms of the associated living and in the subjective sphere, in the direction of a predominance of the immanent dimension of life.

Those theses of secularization start from an interpretation of the celebrated prophecies of Weber and Durkheim.

According to Weber, the unceasing advance of rationalization and disenchantment of the world -typical processes of western modernity- provokes, on the one hand, the emptying of the secular spheres of any religious reference and, on the other hand, the declassing of the religious sphere itself, deprived of any claim to truth and to definition of the meaning of collective living in relation to transcendence. The modern individual gradually becomes insensitive to what is sacred and religious. The progressive abandonment of what is magical and religious is accompanied by an ever-greater appropriation by man of the control of the forces of nature and of the ways in which he relates to them. The resulting dispersion of religion in the pluralism of faiths is further weakened and deprives man of supreme values, condemning him to live in an age without God and without prophets (Weber, 2017).

E. Durkheim, unlike Weber, considers religion as a complex fact, of social origin and nature, with the function of stabilizing coexistence and integration, creating a homogeneous system of shared meanings within society. Like Weber, he nevertheless appears equally peremptory when he states that, with the advance of modernity, God abandons men and their controversies (Durkheim, 1962). With traditional religion left behind, society ends up celebrating the cult of itself, becoming the creator of religion to guarantee, on its own, that connective tissue which is generated precisely by the religious phenomenon and ensures the widest social integration. It is as if society, having moved away from God, had to seek the foundations of its own existence within itself. Indeed, according to Durkheim, societies become creators of the divine by means of a 
projective mechanism whereby religion comes onto the scene to justify the symbolic universe that a given society builds for itself. In this way, it avoids the danger of finding itself at the mercy of single individuals. In other terms, the absence of a religious framework leads to a veritable "cult of the individual" (Durkheim, 1972). For Durkheim it is a process, which presents some highly problematical aspects. He is aware that secularization and individualization are in certain respects inevitable. And he does not call for any return to the predominance of traditional religion. He rather fears that the liberation and emancipation of individuals from religious institutions, in the name of their autonomy, can go to the point of distancing oneself also from society, which he describes as a moral entity, a producer of solidarity.

Both these authors, each in one's own particular outlook on the religious phenomenon, leave an indelible mark on subsequent theories of secularization. The thesis of privatization of religion, for example, inherits both Weber's considerations on the rationalization and the differentiation of the secular spheres from the religious sphere and Durkheim's diagnosis as to the cult of the individual typical of modernity and the hypothesis that religion is a social (and, after Durkheim, individual) construct. Many scholars - although from different points of view - have shared the diagnoses of the two classical sociologists.

\subsection{Subsequent Studies}

The heirs of those prophecies have therefore sustained the thesis of secularization as a loss in importance of religion in social life and have often exasperated the eclipse of the religious phenomenon, excluding the latter's metamorphic character. In this view, religion tends to be made to coincide with one of the stages in the march of western civilization, a stage that is subsequently eliminated by other phases, such as the advent of the scientific revolution. Within this approach, one concentrates above all on what, in secularization, has been lost, without explaining the complexity of the reality that bears witness, sometimes weakly and other times even violently, to the persistence of religion also within modern society. Modernity and religion are considered as mutually exclusive realities: the prevailing of the former inevitably implies the exit of the latter (Yinger, 1957).

In this perspective we find an internally varied and articulated thread of studies that asserted itself especially from the 1960 os in the western context. These studies developed different attentions and accentuations, but in the background of each was the common approach of the theses on secularization. We can subdivide these analyses around the following paths: 
i) there are studies that postulate a progressive privatization of religion;

ii) others concentrate their attention on the desacralization and desecration of religion;

iii) also the transposition of religion to the secular sphere is the subject of analysis of the theories of secularization, as

iv) the interpretation of secularization as a process of liberation from religion and its binding dogmas.

We shall take up the essential features of these ramifications in summary form.

i) According to the hypothesis of the progressive privatization of religion, modernity is characterized by the passage of religion from the public sphere, where it constituted a shared interest of the community, to the private sphere, thus losing significance in social terms. Luckmann talks, in this connection, of "invisible religion" $(1967 ; 1973)$, underlining with this adjective the noninstitutionalized character of the religious phenomenon. For Luckmann, the subjective conscience acquires a greater centrality: the individual must learn to seek the ultimate meanings for himself. Religion thus becomes a "subjective construction" (1973) which is separate from every belonging and connection. ${ }^{1}$ Hervieu-Léger (1986) is positioned on the same line when he talks of "deinstitutionalization of religion", while Davie (1994) uses the well-known expression "believing without belonging" to reinforce the reduction of religion to an exclusively individual matter and the loss of any claim to truth by a sacred cosmos and the social institutions correlated to it.

In agreement with Luckmann, Berger argues for the emergence of a subjective secularization, indicating also in this case the transfer of religion to the private sphere. He highlights the advent of pluralism given the "collapse in plausibility of the traditional religious descriptions of reality" (Berger, 1973: 197). On the one hand, according to Berger (and also Luckmann) there is a progressive differentiation of the secular spheres from the religious sphere, as Weber had already indicated for that matter; on the other hand, in the intimate sphere religion continues to exercise an important role, even though "privatized", so that it becomes the subject of an individual choice or preference. However, it loses its function of social integration, until it is included in the dynamics typical of the modern market economy, becoming at most one of many possible objects of consumption.

1 Luckmann writes: "once religion is defined as a private matter, the individual can choose as best he pleases among an assortment of ultimate meanings - guided only by preferences determined by his social biography. An important consequence of this situation is that the individual builds not only his personal identity but also his own individual system of ultimate significance" (1973: 139). 
Among the theorists of the privatization of religion we find, although in a different form, the idea of the end of religion in modernity: the religion that they trace in the private and "invisible" spheres no longer shapes the conduct of life in the social sphere and no longer touches the experience of the transcendent or, as the historians of religion Otto and Eliade would say, of the sacred. It is rather a question of a subjective religion - in Luckman's sense - thus understood not so much because it is lived by the subject starting in any case from some shared collective reference (within a group or a Church) but because it is built by him/her to his/her liking.

ii) Another line of study has focused attention on the process of "desacralization" (Wilson, 1969) and "desecration" (Acquaviva, 1992) to explain secularization. With Weber, Wilson shares the theses of emancipation of the secular spheres from religion: the religious becomes, if anything, a refuge now at the margins of personal experience. The advance of the process of rationalization and technicalization contributes to this loss of monopoly of wide spheres of social life by religion, which, at that point, loses significance and credibility. A loss that concerns, more in general, the sense of the sacred at both an individual and a social level: it is in this view that he speaks of "desacralization".

Acquaviva insists on this loss stating that, more than secularization, we should speak of a process of "worldliness and desecration" already within the Churches (1973: 167), a typical process of industrialized societies. ${ }^{2}$ In this case, it is the Churches themselves that, in their wish to modernize, renounce the experiences of the sacred. Acquaviva looks on this road with concern, although he points to a positive aspect where the experience of the sacred is provoked to free itself from the scaffoldings that tend to suffocate it.

According to these authors, it is the experience of the sacred that withdraws from social and personal life. In this case, secularization invests not only the secular spheres, depriving them of a religious reference, but religion itself, going within it to empty the rites of their significance, with the failure of the central and indispensable element for every religion. Thus, once again, traditional religions lose their strength within modernity, significantly weakening their ability to aggregate around shared practices able to orient the individual conduct of life.

iii) In the multi-faceted sea of the theories of secularization, there is also a thread of studies that sustains the complete transposition of religion to the secular sphere. Bellah, who agrees with Weber (secularization is understood as

2 The term "sacred" -notes Acquaviva- indicates the place where the meeting between the subject and the "radically other" takes place; this experience constitutes the founding element of religion. 
a differentiation of the secular spheres from the religious one), does not embrace the latter's view of an inexorable decline. Following in the tracks of the American sociologist Parsons, who puts forward a view of secularization as the institutionalization of Christian values within modern society, religion - as Durkheim had already stated - is definable above all for its socially unifying and integrating function. Therefore, where such values are effective, that is where they are institutionalized in a positive manner, we have a "civil religion" (Bellah, 1967, 1970).

Civil religion is a shared set of values derived from the Christian tradition, although the former distinguishes itself from the latter. In fact, the god of civil religion refers much more to order, law and rights than to salvation and love (Ibidem, 1967). ${ }^{3}$

To place the branch of studies that has developed around civil religion among the theories of secularization would certainly require a more thorough in-depth analysis. It is enough to point out that what Bellah calls "religion" makes little reference to the experience of the sacred and the transcendent and is more connected to the "secular" dimension, thus once more reinforcing the perspective of the theories of secularization.

$i v$ ) We will now discuss the last branch of studies, which has gathered wide consensus. Secularization is here considered as a process of liberation of man from the yoke of religion, of its dogmas and worldviews. There are numerous scholars who fall within this branch, with reference to various disciplines. ${ }^{4}$ Let us remember that at the end of the 19th century, the Deutsche Gesellschaft für Ethische Kultur (the German society that dealt with the Prussian government's 1892 Education Bill) proposed to create a technocratic view of social life, placing all its faith in the power of scientific reason, promoting a civil morality independent of religion. In the British context there had been the Secular Society founded by Holyoake in 1846, which called for the possibility that the rights of the citizen should not be conditioned by a Christian confession: the successors decidedly pursued the project of creating a society free of every theological and religious reference (Lübbe, 1965).

3 As is known, in particular in the United States, the reference to this religion has meant impressing, in various stages of the history of that country, a new thrust to secular society, by mobilising people around national aims of a more cultural and political than religious nature.

4 It would be enough to cite modern philosophy and psychoanalysis, which, in various ways, insist on the authoritarian, oppressive role of religion within social life and on the negative implications exercised on individuals' life conduct. 
In the furrow of these views emerged a secularistic vision: in a laicistic society, it is useful and opportune that there should be a retreat of the influence of religion from the claim to want to guide human action. The aim of this manifesto is to guarantee the progress of man and the extension of his individual freedom.

Within this branch of research, rather than putting the accent on the differentiation of the secular from the religious sphere, or on the eclipse of the sacred, or on the privatization of religion, secularization coincides with the passage that leads mankind out of its minority condition to guide it along the illuminated ways of rationality that are strengthened by the scientific revolution, with its technological applications. This is what the founder of sociology, A. Comte (1864), indicated in the early 1800 s, as an evolution of the human species by its exit from the theological stage to arrive, after passing through the metaphysical stage, at the finally positive and scientific one.

The Change of Perspective: towards a Post-Secular Society?

\section{1}

\section{Indications from the Literature}

The studies of secularization, although with different emphases, all adopt a view of history as a progressive succession of phases marked by breaks. The phase of modernity marks the arrival at a stage in which religion is counterposed with the characteristics of an epoch. Concentrating principally on what has been lost, these studies have difficulty in grasping the fact that, in reality, religion and the religious experience do not disappear from the modern scene.

Significantly, those theses are subsequently questioned by their own supporters, who have realized that reality offers a profoundly different scenario from what appeared as an inexact and even "ideological" interpretation of secularization (Martin, 1973: 198; 2005).

Exemplary among others is the case of Cox who, twenty years after publishing a book entitled The Secular City (1966) -which sustained the evidence of the secularization taking place-, published a new book in 1984, entitled Religion in the Secular City: Toward a Postmodern Theology, where the author argues that we are entering a post-modern era of religious reawakening and return to the sacred.

Also the title of Berger's well-known text A Rumor of Angels (1969) was already eloquent in this sense: he speaks of a murmur, to indicate that interest in the sacred and the transcendental dimension has not completely disappeared, and is represented metaphorically as a barely perceptible whispering of angels. 
However, it is especially his text The Desecularization of the World, written in 1999, that suggests the most decisive change in outlook.

Casanova too, in his famous text entitled Public Religions in the Modern World (1994), describes a passage to a subsequent phase, beyond secularization, speaking of a de-privatization of the religious phenomenon. Going away from the predictions developed within a purely illuminist cultural framework, he alludes to the attempt of the great religions to counter the process of marginalization to which they have been subjected by the advent of modernity. The religious traditions refuse to limit their range of action to the simple care of souls but attempt to show the close connection between the importance of ethical-religious questions and the economic-political life of the various national contexts. Added to this are two other tendencies that confirm the change in relation to the expectations: faced with the progressive differentiation between religion and the other social systems, religion tends in any case to play a preponderant role in society; in addition, the decline in faith and religious practice in a strict sense does not affect all the contexts in the same way, so the picture relating to contexts other than the European need to be analyzed better. $^{5}$ The effects of this investment of the religions in the public field are two: a re-politicization of the public and private religious sphere (for which, for example, among some active minorities there is a return to thinking that religion must function as an inseparable element of social integration); a pressing appeal to the existence of transcendent ethical norms that must be placed at the basis of socio-economic and political life.

Starting from a similar assumption to Casanova's, Beyer (1994) states that globalization favors the conditions for a recovery of the presence of religion in the public sphere, speaking of a "global civil religion". A presence that, according to Kurtz (1995), involves questions considered as universally important, as for example the advent of biotechnologies, defense of the environment, global conflicts.

In these authors' line of thought, religion is thus considered as a phenomenon able to mobilize energies within society, playing a crucial public and political role. And if on the one hand the change of perspective that starts to be discussed, enables us to describe the signals of a reality that the theories of secularization were in danger of losing, on the other hand it often tends to

5 Concerning this last aspect, also Martin (2005), criticising the idea of a disappearance of religion, states that on the contrary it shows symptoms of evident vitality, for example with reference to Christianity in Latin America, Africa, Asia. These symptoms lead one to think that secularization limited itself to looking at just a particular social context, i.e. Europe, where the indicators of continuous decline of religion were indeed very marked. 
consolidate a mental habit whereby, also in the presence of significant religious phenomena, one continues to think according to the model of the "disappearance" and, possibly, of the "return", of the "death" and the "triumph" of religion.

The hypothesis of a "return" of religion is explained by the need for an order within the chaos of cultural and social complexity, of a direction of sense for the individual conducts of life: it can also bring with itself a different god from that of the historic European religions (Graf, 2004; Kepel, 1991; Shah et al., 2012).

Revisiting the theories of secularization, the hypothesis we assume in these pages goes in the direction of considering the latter as such a jagged, complex process that already includes dynamics of a religious nature within itself. Hence, "post-secular" society should be understood not as a phase subsequent to that of secularization. ${ }^{6}$ From a closer examination, the same process of secularization originates precisely from a religious phenomenon, namely the Protestant Reformation, given that the latter also includes the social and civil dimension in its moral project, favoring an anthropocentric turn and an immanent pluralistic orientation in its unforeseen effects, as pointed out by Gregory (2012).

The hypothesis is that secularization does not necessarily exclude religion and religiosity: in this way, the religious experience can probably be understood as an experience that does not contradict secularized contemporary society, even though its position and its social and individual role are very different from the past. It is rather a matter of grasping the changes that it has encountered and how the conditions of the contexts of adherence to the faith have changed. If secularization and religious phenomenon have long been understood, manifestly or implicitly, as contradictory, the point becomes trying to consider them rather as opposite poles that do not annul each other but that are in constant tension between them. And it is precisely from this tension that the contemporary religious experience of individuals and organized groups takes shape, highlighting the fact that both the former (secularization) and the latter (religious experience) are non-linear phenomena, and yet intense and involving given that they concern numerous dimensions. Secularization involves all the levels of existence and social life, taking on, as we have seen, different definitions and features. And religious experience can be considered as

6 Terminologically, the expression "post-secular society" is intended to express a "change in consciousness" with respect to the terms in which the process of secularization was previously described and studied (Ballestrem, 2009: 267). For an analytical reconstruction of the question, see the Doctoral Thesis by Nicoli (a.y. 2017/2018). 
a constant of the human being, observable in all historic ages and different civilizations, according to many different modes of expression (Eliade, 1957; Ries, 2007; Hart 2013).

As Rémond (1999) has effectively pointed out, the long description of the progress of secularization over two hundred years has been able to describe only a part of the events; it says nothing about other forms of presence and the perennial nature of the religious fact. To stop only at the religious decline would forget that also in the most secularized society statistically the religious fact remains very important and that it is by far the most massive social fact of a voluntary nature.

\subsection{Some Empirical Observations}

Rémond's statement finds further confirmation in the data of the Gallup Foundation (relating to 2016), according to which $62 \%$ of people in the world define themselves as "religious" and many of them are also engaged in activities of a religious nature; $71 \%$ declare that they believe in God and consider the religious dimension as an important reference point in their daily life; $25 \%$ define themselves as "non-religious", while the number of atheists is around $9 \% .{ }^{7}$ If in some contexts -such as Latin America and sub-Saharan Africa- the religious experience is strongly felt and is expressed through belonging to institutionalized historic Churches and/or to groups often born of the various evangelical ramifications, or -as often occurs particularly in Asia- it takes shape with reference to local spiritualities (Buddhism, Hinduism etc.) and, for the Arab countries, in relation to Islam, in Europe we observe a high level of secularization which is accompanied, however, by the declaration of feeling in any case "religious" by tradition and culture. We shall shortly return to the contents and ambivalences of these declarations.

Research and data on the European context in fact confirm the persistence and the complex structure of the religious phenomena. This happens both because adherence to a religion is an option increasingly "thought-out" and chosen (often unconventionally), and due to the growing religious pluralism configured by reason not only of the historic presence of the great traditional

7 The data quoted here are taken from the 2017 report by Gallup International: End of Year 2016. Global Report on Religion, which covers 68 countries (http://gallup.com.pk/wp-content/uploads/2017/04/Global-Report-on-Religion-2.pdf). Among the various information, the report confirms the connection, which has emerged for some time, between religiousness and socio-demographic characteristics (such as age, income and education: in general, as education and income levels grow higher, religiosity levels tend to diminish). 
religions in their internal structure (in particular, the different Christian confessions), but for the growing coexistence of persons and groups bringing different faiths.

In a text edited by P. Berger et al. (2008), the authors posed the question of whether Europe is really as secularized as people say and think, especially with reference to the United States of America considered as a religious nation. ${ }^{8}$ According to Lehmann, on the one hand, precisely for its development, secularization would seem to be a typically European process, therefore a sort of "exceptional" process of a portion of the world. On the other hand -in the face of some far-reaching social changes, including globalization and international migrations- it is necessary to better understand whether secularization has been only a transitory phase in European history or whether the profoundly secularized continent will align itself with the other continents where religion continues to be important; or whether the other continents, like the people who arrive in Europe with a different religious and cultural background, will adapt to the European cultural-religious frame (Lehmann, 2004).

Although the estimates of the number of believers and the mapping of religious affiliations are not easy to construct, they enable us to assume that $\mathrm{Eu}-$ rope, states Berger $(1999,2001)$, is in any case affected by a certain desecularization. In the perspective adopted in these pages, rather than of de-secularization, we prefer to speak of coexistence, within a post-secular society, of secularizing tendencies with forms of adherence to religion as two tendencies that do not contradict each other but coexist. In this framework, states Pace (2011), the European socio-religious geography appears as a picture in movement; on one side, three quarters of Europeans say that they feel religious, that they resort to some form of prayer, that they feel the need to give a meaning to their action with reference to some form of prayer, in addition to a link to an institutional frame. In relation to traditional religions, both in countries with a Catholic majority and those with a Protestant majority, the reference to the religious dimension takes in a varied range of feelings and actions in terms of belonging, of active participation or generic acknowledgement, of

8 According to various researchers, until the 1970s, the United States and Europe seemed to be proceeding in step in the secularization process (Inglehart, Norris, 2004), but then the USA's destiny seems to have changed, given that the American churches have tended to move as competitors within a crowded market, positioning themselves on emerging needs. Thus, within what has been defined as the "spiritual turn", not only has there been a change in the way of believing of people seeking their own "spiritual way of life" that makes them feel well, but also in the religious offer of goods and services by the religious institutions (Roof, 1993). The debate about spirituality and the relationship between religion and spirituality is very wide, both in the USA and in Europe; for a useful introduction see Giordan (2007, 2016). 
total or partial affiliation to the contents of faith. On another side, alongside the substantial nucleus in Europe that continues to define itself as Christian or belonging to the historic Jewish minorities, we see a growth -as a result of the grafting of new cultural and religious stocks through the migratory processesof forms of Christianity referring to new Churches, of mainly Asian, African, and Latin American origin, which build on a spirituality mainly without dogmas and apparatus. ${ }^{9}$ Alongside this is an increasingly important presence of Islam, though not so marked in absolute numerical terms: the estimated presence of Muslims in the countries of the European Union does not on average exceed $3 \%$ of the population of the principal countries with large-scale immigration (Ibidem). ${ }^{10}$

In general, the social and cultural environment of many European societies is still marked by the presence of the historical religions, although new forms of religion seem to emerge alongside them. If we wish to trace "an ideal map of religiosity of Europeans, on the one hand, the different meridians and parallels tend to show the long history of the religions that civilized this or that area of Europe, and on the other to highlight a morphology of the religious terrain which is still fed by a common humus, but which is dotted with many gardens and vegetable patches cultivated directly by individuals" (Ibidem: $65^{-89}$ ).

The data of the Pew Research Center, too, confirm that the majority of Europeans (about $70 \%$ ) continue to consider themselves as Christians even though they do not regularly attend the Church they belong to (only $22 \%$ say they are

$9 \quad$ Pace refers to the data of the European Values Study (Evs): prudent estimates state that about 37 million Europeans belong either to Pentecostal churches of protestant matrix or to new charismatic and neo-Pentecostal churches that have arrived through immigrants. See also Halman et al. (2008, 2005).

10 The 2018 Report of the Pew Research Centre, referring only to the countries of Western Europe, gives an estimate of $4.9 \%$ (including Norway and Switzerland, with the highest peak values in France $-8.8 \%$, UK $-6.3 \%$ and Germany $-6.1 \%$ ). As is known, however, there is an objective difficulty in measuring the presence of the different religions in $\mathrm{Eu}-$ rope. Often the reference consists of the residence permit of the immigrants who, in this case, are the principal bringers of the Islamic religion (apart from some European regions where Islam is a historically rooted local presence): this is evidently a vague figure as geographical origin cannot be taken as a secure source for stating automatically that all the inhabitants coming from countries with a predominant Muslim tradition adhere to that religion and/or are practising believers (whether in their homeland or where they have emigrated to); in addition, the minorities also living in these countries should be considered; in some cases, they emigrate precisely by reason of their different religious affiliation from the official one (in this connection see Chapters 6, 10 and 14). 
practicing). ${ }^{11}$ The non-practicing ${ }^{12}$ form the majority in all the Western European countries, with particularly high peaks in the Nordic Countries (reaching, for example, $68 \%$ in Finland against 9\% practicing; $55 \%$ in Denmark against $10 \%$ practicing), with the exception of Italy (where the percentage of nonpracticing and practicing is equal, at about $40 \%)$.

Although Europe appears as a secularized region, in many of the countries studied in the survey the non-practicing believers far exceed those who state they are non-believers (atheists, agnostics or, more in general, the so-called "nones"). And also, even with the recent immigrations from the Middle East and North Africa, there are in any case more non-practicing Christians than people of other religions, considered all together. According to the Pew Research Center, these figures are explained by the fact that what remains particularly rooted in the individual life experience is the Christian identity as the cultural badge in Western Europe, an identity not in a merely nominal sense.

Furthermore, although there has been, for some time, a strong tendency towards a decline of Christianity in various countries (e.g. Belgium, Finland, Ireland, Holland, Spain and Portugal), other countries, at the same time, exhibit a relative stability or a more modest decline. The process of secularization varies considerably from country to country. ${ }^{13}$ It should then be defined also in the light of the various historical vicissitudes of the different nations and of the relationship that each country has maintained with the religion or religions present within its territory in the phase of construction of the modern State. ${ }^{14}$

11 The report is available at http://www.pewforum.org/2018/05/29/being-christian-in-western-europe/. The data refer to a survey carried out in the period April-August 2017 in 15 countries of Western Europe, through 24,00o telephone interviews administered to adults. The processes identified have been continuing for some time also in the countries of Eastern Europe, as for example in Romania where, already ten years ago, there was a very high percentage, with almost $98 \%$, of people declaring themselves to be "Orthodox" with $30 \%$ practising (Kosela, 2007).

12 Those are considered as such who define themselves as Christian but attend the places and activities of worship only a few times in a year. Those who attend at least once a month are considered "practising".

13 In this connection it should also be pointed out that in some cases (e.g. Germany, Sweden, Denmark, France, UK) the smaller decline recorded over recent years starts from an already fairly high level of secularization.

14 In fact, in some cases religion has contributed historically to the formation of the national identity, rooting itself in people's experience beyond the declared affiliation. In other contexts, freeing from dictatorial regimes has meant distancing oneself also from the dominant religion which, with respect to those regimes, had adopted ambiguous attitudes, while in yet other cases religion has played exactly the opposite role, acting as a critical 
And if, in general, the religious phenomenon seems to have become more problematic and fragile than in the past, this does not mean that it has lost all significance in relation to personal biographical paths. This is evident, for example, in the frequent visits to sacred sites, as testified by the widespread phenomenon of pilgrimages in many regions of Europe (Cipriani, 2012; Damari, 2016) $)^{15}$ and to places of worship (also those less institutionalized) or in the persistence of the demand for solemnization of certain decisive moments of existence. ${ }^{16}$ This finds confirmation in the case of Italy, which occupies a particular position in the Western European panorama, as indicated: empirical research shows a structured, complex, and vital co-presence of secularizing tendencies and forms of religiosity. ${ }^{17}$ If for example we observe the religious practices, with reference to Catholicism, we note that the bond between the Italians and the Church has been loosened but has not been broken (Garelli, 2011). This is well confirmed by the request for sacraments even by the more uncertain and hesitant believers. ${ }^{18}$ The religious sense continues to be widespread among Italians who do not completely renounce turning to the Catholic Church, even if in different ways than in the past. In fact, although personal discretion is widespread as regards the choice of timing, manner and forms of participation (Diotallevi, Allievi, 2004), it is not possible to talk of a definitive abandonment of religious practice, but rather of a religiosity seeking new

element towards the system, gathering around itself the resilient forces (consider, for example the case of Spain with the Franco dictatorship and the case of Poland before the fall of the Berlin Wall).

15 When the Council of Europe in 1987 recognised the importance of the religious and cultural paths running through various European regions, a new season opened up for adherence to these itineraries (see, for example, what happened with the "Way of St. James").

16 We refer, more precisely, to the so-called "rites of passage" i.e. those that mark the three cardinal moments of existence, solemnising birth (with Baptism in the Christian tradition), the union between two persons (marriage) and death (funeral).

17 See in this connection the various studies and sociological researches in Italy: among others, Garelli (1995, 2003, 2011); Gattamorta (2009); Abbruzzese (2009, 2010); Pollini (2012); Berzano (2017a, 2017b).

18 Sacraments constitute the heart of Italian religiosity -and, more generally, of Catholic religion- as evidenced by the persistence of their celebration also by those who consider the faith only as a cultural tradition. In addition, if sacraments risk losing their specificity that of being the meeting point between immanence and transcendence and of linking the individual to the community- they represent one of the major challenges for the Catholic Church because of their importance among people even in the secularizing pressures. The importance of sacraments emerged also from a recent research in Italy carried out by a group of researchers of ARC, Center for the Anthropology of Religion and Cultural Change, Catholic University of Milan, and the Italian Episcopal Conference during 2015-2016 (cfr. the Survey Report drawn up by ARC, 2016). 
modes of expression, which are able to make greater use of the individual's contribution within a traditional, communitarian frame.

The European picture is therefore in movement. The question of secularization is more complex than it had been presented initially by the different branches of study: in fact, within the category of those who define themselves as believers there appear the "intermittent" and the "doubtful" who, unlike the atheists and agnostics, do not abandon their path of faith. In other words, the fact that the religious experience in secularized society is profoundly crossed by doubt does not seem to preclude the possibility of a spiritual and religious search by those who manifest it.

At the same time, from the research there also emerges a more "disenchanted" view of reality, which expresses itself for example in the gradual abandonment of some fundamental beliefs: the existence of life after death, the divine judgement of history, the role of original sin. This phenomenon reflects some typically modern secularizing dynamics, linked to the oblivion of topics that bring great questions, such as death, evil and good, which influence the religious representations of believers and adhesions to given contents of faith, profoundly modifying them. ${ }^{19}$

\subsection{The "Secular Age", Secularized and Religious}

The evidence of the complex relationship between secularization and religiousness has led a number of researchers to associate with the term "postsecular society" a wider meaning than that which aims to record simply the passage from one historical age to another, indicating rather how religion persists within an increasingly secularized frame. ${ }^{20}$ The "dialectics of secularization" -as discussed by Habermas and Ratzinger (2005) - would show the ambivalence of the processes of secularization: on the one hand, in the name of emancipation from religion -and from its dogmas, values and meanings, from its truths, moral authorities, institutional forms-it was expected to disappear; on the other hand, however, this eclipse has not occurred.

In clarifying Casanova's thesis, Habermas (2005) maintains that religious communities persist also within a more secularized horizon. For the German thinker, religion continues to exert an influence in the public spheres of the single countries, as well as signaling the phenomenon of pluralism of forms of

19 In reality, these are questions set aside decidedly by contemporary culture in general (see for example the eclipse of the question of death for the contemporary man: among others, cfr. Bauman, 1992).

20 On the notion of post-secular society understood in a broad sense see, among others: Habermas (2006); Belardinelli (2006); Ferrara (2009); and especially Taylor (2007). 
life following especially the processes of immigration. This opens up new challenges in terms of the necessary mediations by the religious authorities with the social contexts, on one side, and of opening towards religious thought by post-secular societies on the other.

In the change of outlook on post-secular societies, secularization can ultimately be defined as a complex process, which, while causing breaks with the past, does not entail incompatibility with the religious phenomenon, so that there would not be a phase after secularization of returning of religion as if it had disappeared for a period from social and individual life. The religious phenomenon, despite transformed with respect to the traditional forms, and although fragmented and sometimes contradictory, remains even within the secularized contexts. This interpretation enables a widening of the scenario in which to investigate the phenomenon of religiousness, posing new questions that start from the recognition of a co-presence of secularizing tendencies and religious inclinations.

As stated by C. Taylor -one of the most authoritative researchers into religious phenomena-,

The whole culture experiences cross pressures, between the draw of the narratives of closed immanence on one side, and the sense of their inadequacy on the other, strengthened by encounter with existing milieux of religious practice, or just by some intimations of the transcendent. The cross pressures are experienced more acutely by some people and in some milieux, but over the whole culture, we can see them reflected in a number of middle positions, which have drawn from both sides. (2007:595)

This scenario is well expressed by the metaphor, suggested by $\mathrm{H}$. Joas, of the sea in a storm: like the sea, our history is marked by strong secular waves but also by religious back-currents that often revitalize religious traditions or facilitate new religious options (2014).

In this perspective, the view of history adopted by Taylor is not subtractive but additive: the turn of historical events is conceived as an uninterrupted succession of events, however non-linear it may be, that also presents some constant nuclei, although subject to change. Among these nuclei, there is precisely the phenomenon of religion and religiosity. Recognizing how secularization has undoubtedly exerted a powerful influence on the religious phenomenon, he shows how this has nevertheless not caused its disappearance: the religious motivation "was and is evident in the creation of new forms, replacing those disrupted or rendered unviable by these 'secularizing' agents. The vector of this whole development does not point towards a kind of heat death of faith" (Taylor, 2007: 437). 
Thus, despite the weakening of the faith, secularization causes a new position of the sacred and the spiritual in relation to the individual and social life and challenges religion to examine its contents to verify what its message is regarding a historical period. And this "new placement is now the occasion for the reorganization of spiritual life in new forms, and for new ways of existing both in and out of the relation to God" (Ibidem).

Significantly, Taylor's text analyzing these changes is entitled, as we have said, A Secular Age, inviting us to go beyond the more diffuse term "postsecular" unless we use it taking into account the complexity of reality. Also, for Joas the secular age is an epoch that is not marked by the absence of religion and faith but by the mixing of religious and non-religious elements, with a greater complexity of personal experiences.

Starting from this awareness and keeping in the background the idea of secularization as "a change from a society where believing in God is unchallenged and indeed, unproblematic, to one in which it is one option among others, and frequently not the easiest one to embrace" (Taylor, 2007: 3), in the next paragraph we shall try to reinterpret European post-secular society as an interweaving of "cross pressures" on religious experience and within which it moves.

\section{Post-Secular Society: an Interweaving of "cross pressures"}

The most evident trends in the process of secularization that give rise to "cross pressures" on the experience of belief, to the point of changing the conditions of the context in which it takes shape, are those that Weber expressed with the two terms of "disenchantment" of the world and "rationalization". These are two closely interconnected movements that influence each other and affect both the societal structural factors and personal experience.

Disenchantment of the world, as already mentioned, consists in the gradual loss of the magical-sacral reference, which goes in step with the growing belief of human beings that they can control the forces of nature by means of a calculating rationality. These processes, in late-modernity, constitute an indisputable fact. Disenchantment and rationalization produce multiple effects on reality, but not all these effects are necessarily negative as Weber argued. ${ }^{21}$

On the one hand, having removed every magical-sacral reference, the disenchanted man finds himself effectively less constrained by external forces and

21 The discussion that follows is based primarily on the already-mentioned reflection by Taylor in A secular age, where the phenomenon of disenchantment is reinterpreted, in its positive and negative aspects, starting from the focus on the experience of modern man. 
able to manage his existence and his relationship with the world by himself; in short, he becomes more autonomous. In parallel with this process, a new subjective demand opens up, for understanding, participation and action, which in Modernity becomes increasingly important. The disenchanted man is no longer satisfied with being a passive spectator in the experiences that mark his life -which include the religious experience- but demands the possibility of participating actively, of becoming their protagonist. ${ }^{22}$

On the other hand, in order to be able to happen, disenchantment requires an assumption to be satisfied: that is to say, it is necessary for the subject to make a veritable break with respect to the link between himself and the world, which only from that moment can be perceived as an objective, separate and external reality and only as such controllable. According to an effective metaphor of Taylor's, the self, from "porous", becomes "buffered", separate from everything and everyone (Taylor, 2007: 38; Taylor, Dotolo, 2012). This break with the world takes on various forms in reality.

The first form directly concerns the link between the self and the deity which, following the break, undergoes a veritable "uprooting"23 from the earthly world: there is thus a passage from a world where everything refers to a god, i.e. to a meaning other than and external to the self, to a world in which the signs of the deity disappear and the idea that the divine reveals itself in our world appears even incomprehensible (Scruton, 2015).

The second form of break concerns the link between the self and the community, that is to say that social space where the individual defined his identity by virtue of his belonging to a group, which in turn qualified itself in the light of a sacred and divine foundation. The community guaranteed the condition of a belief shared among its members and sustained the biographical paths of the latter. Thus, if the distancing of the individual from the community, which has occurred in the disenchantment, has on the one hand enabled the modern man to recognize himself and assert himself as a single, unique individual, on

22 These are aspects amply discussed by Habermas (1986). According to the author, the decentralization of the religious vision of the world, and the freeing of the vital world from a highly dogmatic dimension, open for the individual the possibility of clarifying and verifying in first person the reasons on which the various 'claims to validity' rest, thus allowing the production of a criticisable understanding. Disenchantment of the world thus has the merit of opening up a new potential of rationality in the vital world; a positively qualified rationality which is distinguished from the instrumental one by the fact of being oriented to understanding and founded on an interpersonal relationship.

23 The term takes up A. Bilgrami's expression "deus deracinus", which puts the accent on the act of eradicating the divine roots from the world, which, as a result, becomes an ugly, desacralized place (Warner et al., 2013). 
the other hand it has transformed the construction of the identity into a burdensome task, to be achieved in spite of the dissolution of the community.

A third form concerns the link between the self and the other person, in other words the social relationship. Disenchantment, in fact, if taken to its extreme consequences, requires total autonomy from the "buffered" self, which must erect barriers against everything that escapes its control. The link with the other becomes devoid of usefulness in the eyes of a person who considers reality from the point of view of a calculating rationality; thus, in the majority of cases, the other ends up as an obstacle to modern man's project of autonomy and independence.

The process of rationalization intertwines with disenchantment. It consists in a movement of a historical nature towards a progressive predomination of the instrumental, calculating attitude, with respect to action oriented to value and meanings.

In other words, among all the possible ways of relating to reality, what is progressively affirmed in modernity is a rational view of the world, based principally on scientific knowledge and technological control (Inglehart, Norris, 2004). At this point, it appears evident that modern man, moved by that quest for comprehension, participation and action that has been freed in disenchantment, chooses to avail himself of this worldview, which rationally explains every event, including those linked to the religious phenomenon. With the consequent refusal of all contents and meanings that do not fall within the criteria of instrumental rationality in the strict sense, and which in the eyes of the disenchanted man therefore appears devoid of meaning: in the case of religion, the dimensions of mystery and grace, which by definition cannot be explained in rational terms, are excluded.

From the process of disenchantment and rationalization "cross-pressures" unfold, which influence the religious experience. We shall dwell in particular on some of them: the subjectivization of this experience, with its positive and the more problematic aspects; the question of social bonds; the change of the relationship between transcendence and immanence.

\subsection{The Challenge of Subjectivity and the Question of the Fluctuating Religion}

In many European countries, as already mentioned, the disenchantment of the world has implied a loss of significance of traditional religions or, in some cases, a sort of ex-culturation of Christianity (e.g. in France) as stated by Hervieu-Leger (1986) or, more in general, a sort of de-Christianization of the European context (Lehmann, 1997). The shrinking of the space occupied by the more institutionalized religions has been accompanied by a widening of 
the space in which individuals, with different levels of freedom, have renegotiated their religious beliefs, in favor of a less strong bound to dogmas and social ties.

These processes pose some challenges, in particular to religious institutions, to the way in which they propose religious practice, to their ability to seek mediations between the more institutionalized dimension and the more subjective one of belief, considering that religion continues to be an important point of reference. At the same time, however, also at a level of religious experience we see the same loosening and weakening of bonds that runs through the wider social life, and individuals often abandon themselves to the continuous fluctuation of things, up to the experience of insignificance that leads them to pursue consistent reasons for going forward by resorting to the numinous. So if on the one hand there emerges a quest for greater subjectivity in living the religious experience also with reference to more traditional forms of affiliation, on the other hand, what is sought continuously within religious experience is the uniqueness of one's own self, its sacrality, according to individualized paths also in the direction of "alternative spiritualities".

As far as the first aspect is concerned -the relationship between the institutionalized dimension and the more subjective dimension of faith- we are dealing with an equilibrium that is always difficult to maintain. It concerns the relationship between "religion" and "religiosity". In this respect, it is useful to refer to another classical sociologist, G. Simmel, who -unlike his contemporaries Weber and Durkheim- more than focusing on the modern process of secularization, approaches religion starting precisely from the personal experience that individuals make of it. For Simmel, religiosity is the space in which the subject gathers himself with respect to the mystery, it is the place where the center of the individual safeguards itself, i.e. the opening towards the transcendence; religion instead is the objectivated historic form that emerges from the continuous interaction over time of a plurality of persons. Religion is therefore concerned with the collective cultural translation of religiosity; it takes shape through the organizational modes of religiosity. ${ }^{24}$

A problematic aspect of religion is, in Simmel's view, the tendency to unify the religious behaviors of its adepts around norms considered universal to be applied homogeneously to everyone. This has led, over time, to ignore all the more personal dimension of religious experience and -in the more specific case of Christianity- of the concept of salvation, i.e. of the dimension

24 Simmel overturns the usual concept, whereby religion must already be present in order for religiosity to arise, and states that "religion does not create religiosity but religiosity creates religion" (1997: 150). 
questioning individuality. And it has led to a failure to consider adequately the importance of cultivating one's own talent, demanding uniform behavior from all instead of drawing on the uniqueness of each person. According to Simmel, if God, for the believer, is placed at the center of existence of the human being, then He is not counterposed to his individuality. Therefore, religiosity constitutes a space where the subject protects his experience of transcendence even from the possible absorption of religious structures. Subjectivity is always a subjectivity in relation to another you, a beyond self, the world, history, the divine. ${ }^{25}$ For Simmel, safeguarding the person does not in fact mean opting for the absence of organized forms. With reference to the religious sphere, he points out that one of the functions formerly carried out by the Church was to assert the value of the person as unmistakably unique. The point is that, as happens for all instituted social forms, also religious ones can threaten to monopolize the people, thus pushing them to realize their identity outside them. This has negative implications for religion itself: the latter-as Simmel predicted in the early 190os- risks retreating into the private, losing the possibility of representing a "Heimat" for even the most individualized believer. In this way, the Churches themselves, as institutions placed at the service of the perpetuation of the faith over time, and the mediation of the contents of belief are weakened, as they are sustained by believing persons.

Religiosity and religion interpenetrate, in a constantly dynamic equilibrium: religiosity constitutes the beginning of renewal of religion that remains a significant source of symbolic values also for social life. In order to prevent the breakup of religion, Simmel considers it as necessary to create spaces where the heritage of tradition is placed more in relation to the recipients, to their needs, thus recognizing the possibility of a personal, creative contribution.

So on the one hand, disenchantment causes us to continually rethink the relationship between the more institutionalized dimension of belief and subjective experience, so that the two poles coexist and supplement each other, but on the other, disenchantment that absolutizes and strengthens itself in the increasingly technical, nihilistic and fragmented cultural frame of contemporary societies, may lead to the construction of that "God of one's own" of which Beck speaks. With this definition he indicates a religious where "a God of one's own might well be template for a life or a space of one's own" allowing the

25 Simmel is in fact critical towards the absolutization of the modern process of individualization that leads to the impoverishment of the subject because the subject comes to find himself without bonds, without the world - an abstract Ego. This dualism that runs through the modern subject threatens to eclipse its original duality; the subject is, for Simmel, a "whole man", i.e. both an individual in himself, peculiar, and an individual projected outside himself, social (Martinelli, 2014). 
subject to construct his own "sacred canopy" (Beck, 2010: 14, 16). ${ }^{26}$ The "God of one's own" is, in fact, a god with whom one intimately interacts into the daily experience of human life, beyond the religious dictates and dogmas. However, this "God of one's own" tends to become "a commonplace, banal and trivial. It has been devalued by endless repetition. No distinction is made any longer between God and idols. We move in a world of multi-faith quotations whose source and meaning we do not know"; it is sufficient to look through "a catalogue destined for the New Age market - for the God of our own choosing has become venal" (Ibidem: 13). That "God of one's own" becomes a god filtered by the awareness about our own life, knowledge, a god similar to us and reflecting our own image: it is the individual that builds his own religious cover and decides his own faith. This is an attitude that does not exclude the adherence to a doctrine or a Church: the individualistic forms of affiliation to religion are in fact numerous, as long as subjectivity desired. This shapes a fluctuating religiosity, where religious faith can freely be conveyed, like any other content, provided that it does not require any privileges. In the mare magnum of cultural resources made available in the mediatized aesthetic space, there is also the religion as a symbolic resource equivalent to many others.

Heelas and Woodhead (2005), in considering the relationship between religion and spirituality -which in Europe, unlike the USA, implies a progressive marginalization of religion by spirituality-argue that, despite the indicators of secularization, the sacred does not disappear but is redefined in tune with the massive "subjective turn" of modern culture described then by Taylor: this "subjective turn" is a turn to subjective-life, a life lived in deep connection with the unique experience of the self in relation to one's own emotions and passions, which shape a subjective life-spirituality.

Within this orientation, it is not to be excluded that a breach may open to the return of the numinous (Casement, Tracey, 2006), until religious experience undergoes torsions approaching the neo-magical. Paradoxically, the disenchantment is countered by forms of re-enchantment with the world. The neo-magical attitude uses religious forms to promote an optimistic relationship with reality. ${ }^{27}$ Magic has its own functionality, because it reintegrates the

26 The term "sacred canopy" used by Beck is taken from a famous Berger's text (Berger, 1967).

27 As Malinowski wrote, "the function of magic is to ritualize man's optimism to enhance his faith in the victory of hope over fear. Magic expresses the greater value for man of confidence over doubt, of steadfastness over vacillation, of optimism over pessimism" (1948: 70). 
individual into some system of values without binding it to Churches (De Martino, 1962): each one tries in fact to propitiate the positive forces to his own advantage. In this frame, contemporary individualism marries easily with neomagical attitudes while religion tends to produce communities. In full conformity with the contemporary consumeristic culture, the reference to magic satisfies the need for immediate solutions and a low acceptance of normativity. It dissolves the complex link of the relationship with God, with the other and the community, paradoxically reinforcing the technical-rational dimension of collective life, within which the otherness becomes abstract.

In conclusion, disenchantment produces cross pressures, sometimes contradictory ones, on the religious experience: on the one hand, it pushes for a useful revision of the relationship between the personal experience of the faith and the order of instituted forms; on the other hand, a greater subjectivization of the religious experience can mean a total unbalancing on the individual side which produces by itself what to believe in, within a fluctuating, basically immanent religion.

\subsection{Reconstruction of Bonds and Emergence of Closed Communities}

The weakening of bonds brought about by disenchantment produces unexpected side effects. On the one hand, the "buffered Self" becomes effectively able to keep under control, even manipulate and construct, wider and wider portions of reality, but on the other there grows a sense in him of insecurity and disorientation, produced precisely by the different forms of break carried out. In fact, the bond, while forming a constraint in some senses, is in other senses a promise of support to the individual in his biographical path.

Not relying, instead, on a network of bonds (whether with the deity, the community or the other) that confers a meaning to existence, the modern man, disorientated, exposes himself to numerous options that post-secular society places before him: "at one moment, we understand our situation as one of high tragedy, alone in a silent universe, without intrinsic meaning, condemned to create value (...) a flattened world, in which there aren't very meaningful choices because there aren't crucial issues" (Taylor, 1991: 68).

In this disorientation, a question of rooting emerges: it often goes in the opposite direction to systematic eradication, to eclectic nomadism, to the aimless wandering and pure universalism celebrated by contemporary culture. It expresses a need of identification with something: a demand that goes in the direction of communities considered to be salvific. Not by chance, in the age of individualism, which already the classics of sociology thought to become more and more unbridled, there is an increase in the fusional forms of community 
and the so-called "gated communities". ${ }^{28}$ The more the process of demolition of the real and of meanings advances, the more a space is created for the search for a new foundation, understood as something solid to be subtracted from the discussion and from the insubstantiality to which the whole existence seems to be subjected. In this line, religion - together with other references, such as territory, ethnicity and tradition - belongs to those distinctive elements that are not suspected of being affected by the virus of fragmentation: religion becomes a powerful bond, able to contain and counter the crumbling of social bonds and cultures. It becomes a particularly strong reference for reaffirming some roots that allow some form of personal and collective identification, in the face of relativism and chaos.

Thus, wishing to recover what has been lost, it is done with the idea of ordering the world in a fundamental difference between a "we" and a "you", between an inside and an outside. And when the "sacred" comes on the scene, religion can even acquire radical, fundamentalist features, without excluding violence through organized groups. ${ }^{29}$

Religion is once again subjected to cross pressures: on the one hand it can provide that "Heimat" that the believer seeks in order to be able to give a meaningful direction to his experience, but on the other hand it lends itself easily to being made to coincide with a reassuring element for the individual identity and a fundamental answer to the need for protection from the threat of insignificance. And if religion has often surfaced in forms of creative and collective resilience to the problems produced by the dominant model of development or of critical protest for a forward-projected social redemption, it is here evoked as a compensatory refuge, functioning as a protected technique mediating values (De Martino, 1958). In this frame, the values that religion serves to mediate are those originating particularly from tradition. Religion is thus reduced to becoming a bulwark to keep itself firmly in the past, even though it competes with other repertories that contradict it (in particular the media), with no concern over the fact that the values of which it makes itself a bearer are often only affirmed in words but belied in facts.

28 Among others, refer to Bauman (2001) who defines this kind of aggregation "peg communities", i.e. spaces where people seek pegs on which they can together hang their fears and anxieties.

29 The relationship between the sacred and religion is, as is known, a theme that recurs constantly in literature as in social life; it is particularly delicate because, precisely in the name of the sacred, religion takes on and justifies violent features (among others, see in particular the work of R. Girard, for example 1972, 1982; for a recent research into the matter, with reference to the European context, see Lanzetti, 2018). 
There are some emblematic data of the already mentioned Pew Research Center from which an orientation emerges, among European (Christian) believers, to use religion as a symbolic repertoire called upon to assert an identity, or alleged identity, against, in particular, what is "different", represented especially by the immigrant. The data show, for example, a greater frequency of negative opinions among believers (both practicing and non-practicing) towards other religions, especially Islam. This raises a number of thorny questions, such as the one relating to the meaning of "Christian identity" and, consequently, to the role of religious contents and the relationship between religion and culture. ${ }^{30}$

In this connection, Brubaker (2016) speaks of a "reactive Christian identity" to indicate how the topic of Christian religious identity has become a question around which many other questions raise in secularized Europe - such as the defense of individual rights (freedom of expression, individual autonomy, gender equality, toleration of homosexuality etc.) that are perceived to be threatened by the settling in one's own territory of cultural and religious groups considered to be anti-modern. ${ }^{31}$ Those who consider themselves as believing Christians and, in particular, non-practicing, call for a reduction in immigration to Europe more easily than do the "nones", especially if coming from the Middle East and sub-Saharan Africa. Brubaker sees an "assertive secularism" which, unlike the "militant secularism" understood historically as opposition to institutional power and the influence of the authority of the Church, is now aimed against Muslim immigrants and their descendants: this is a tendency which, in the author's view, concerns especially some populist movements, which appeal to religion in defense of the West, although what they are interested in is not religious values in the strict sense.

As it has often happened in history, religion becomes a cultural badge used in defense of questions that in reality are not closely connected with religious contents (in this case, the Christian ones). The process of "culturalization" of religion is pursued, again according to Brubaker, for a dual gain. On the one hand, it allows Christianity to have a position of privilege as "culture" within a context -the secularized European one- in which it has lost that privilege as a religion, given the liberal State's commitment to neutrality in religious matters. On the other, it enables minority religious practices, redefined as cultural, to be restricted in a way that would not be possible, given the option of liberal States toward religious freedom.

$30 \quad$ For a detailed account of related ethical issues, see Chapter 2.

31 The encounter, or the confrontation, between Christianity and Islam is often reduced to a pair of concepts: liberal and illiberal, individualistic and collectivist, democratic and authoritarian, modern and retrograde, secular and religious. 
Roy (2016) takes up a similar position when he states that European Christianity, from being a faith with its rites and practices, has become a mere cultural badge that easily risks degenerating into a neo-ethnic badge with closures towards the outside. In this frame, the continuity between Christianity in Europe and modern secularism is no longer based on values considered universal and felt to be common to both positions. If we wish to speak of continuity, this is built, if anything, around the idea of identity: the Christian identity is understood in a merely "cultural" sense, excluding the religious values in the strict sense from those that are instead defined as "European values", made to coincide mostly with individual rights.

As highlighted by various scholars of religion, where religion, for one reason or another, has been historically "culturalized", in reality it is no longer a religion, but something else, thus also compromising the conditions for a balanced religious pluralism, given that religions end up competing miserably with one another rather than allying themselves around common, shared questions, therefore nurturing the fundamentalist traits that are hidden in each of them (Soeffner, 2014).

The questions are very complex. The breaking of intersubjective and social bonds produces cross-pressures on the religious experience, in the direction of exasperating the search for strong bonds, reassuring identity, not without the danger that religious groups take on radical traits. On the other hand, however, this shows that the individual without ties is an abstraction and that he therefore seeks a position within significant relational networks.

In this sense, the search for ties finds, in belonging to religious groups, a pertinent response to this need, given that the religious dimension is a profound element of the believer's identity and lifestyle, with positive effects on social coexistence when the form of these aggregations is peaceful. It would suffice to mention, among the many experiences of this kind, the case of the so-called "ethnic" communities and missions made up of immigrants, present in many European cities with reference to the Christian context or, in the case of the other religions, the numerous places of worship and the cultural associations that have an explicit reference to religion. In particular, the ethnic missions have a long history in Europe following the large-scale migrations in the second post-war period: suffice it to think of the case of the Italian, Spanish and Portuguese migrants in the cities of Central and Northern Europe where, in many cases, they favored routes of integration not counterposed with the local host society. ${ }^{32}$ Their role is to provide places of worship but also of

32 Among the numerous studies on the subject, see: Prencipe (2010) and, with reference to the European case as a whole Tassello et al. (2011). For the Italian case, see, among others: Golinelli (2011); Ambrosini (2016); Ambrosini et al. (2018). 
assistance, education, solidaristic commitment and production of culture. ${ }^{33}$ These structures can carry out an important task of "ferrying" into the local ecclesial communities, after offering the possibility, for an initial or more prolonged period, of expressing themselves in their own language and according to the traditions of their communities of origin. As to the risk of a possible retreat within their ethnic, cultural and religious communities, there is also a tendency, if and where present in the arrival society, to consider migrations as a transitory phenomenon and religion as a parallel element in relation to the immigrants' experiences. In this case, the result is often a limited adaptation and a poor inclusion by the migrants into the structures of the host society. On the contrary, where the presence and religious experience of the migrants are considered as structural phenomena of the host society and as a vital and vitalizing part of the activity of the Churches and local religious groups, virtuous processes are set in motion with positive side effects, insisting on the value of the religion in relation also to broader social ties. ${ }^{34}$

\subsection{Transcendence and Immanence}

The effect of the interweaving between disenchantment and rationalization is the detachment between immanence and transcendence. If indeed the man of the Middle Ages or, as Taylor puts it, the man of Latin Christianity considered the two polarities only simultaneously, because every immanent occurrence could not have an autonomous significance but had a transcendent foundation, for the disenchanted man this co-presence has become inconceivable. The disenchanted view of the world is based on the assumption that no immanent phenomenon can at the same time have a transcendent foundation, because otherwise it would escape the control of man; on the contrary, it must be possible to explain everything rationally.

The gradual unfolding of a technical society pushes decidedly towards the immanent option. This type of society -leaning on individualization and fragmentation of social bonds, economic and financial expansion, technological progress and bureaucratization, detachment between functions and meanings- has legitimized itself thanks to its capacity to increase the possibilities in a constant, ever-greater manner, together with the predictability of what occurs, and to overcome the limits posed by the institutions and the culture with their constraints of place, memory, meanings and values. In this model, on the one hand there arises the individual; on the other, the increasingly

33 See in this connection the research as to the role of religion in the process of integration of migrants into the new cultural context contained in Part 4, where it is also stated how religion-, faith-based organizations contribute to integration and social cohesion.

Refer to the experience described in Chapter 16. 
systemic organization that responds to the growing demand for individualization. For the system, the individual is a bearer of needs to be satisfied: for the individual, the system is the interlocutor that must guarantee the maximum individualization by reducing social obligations to the minimum. As in a circuit that continuously feeds itself, individualization reinforces the process of technicalization of society. The growing demand for subjectivity coming from individuals in the advanced societies is satisfied (at least this is the dominant assumption) through the increase in the systemic power, able to broaden the instruments infinitely, beyond the meanings.

The technical element is one of the factors that give shape to post-secular society by acting within it; it is what has been increasingly raised to a system shaping a technical society (Magatti, 2018). Disenchantment and rationalization thus reach unheard levels in the age of techno-science, where the pervasive capacity to increase the possibilities without limit requires the individuals to remain continually open. Transcendence is exchanged precisely with this unconditional opening to new possibilities here and now. ${ }^{35}$ It is as if the opening of man to the beyond were shifted onto a completely horizontal axis, nevertheless able to play this immanence in a highly dynamic way. It is indeed an insistent immanence that candidates itself to give rapid, relevant answers regarding people's existence, if we think of the role acquired by consumption, and of the capacity of technical systems to give solutions to day-to-day problems and to the possibilities of optimization and manipulation of reality (and life), up to the hypothesis of overcoming the fragility and mystery because they are in contradiction with the efficiency, predictability, performativity required by contemporary capitalism. Significantly, already W. Benjamin defined modern capitalism as a "religion" because it "serves essentially to allay the same anxieties, torments, and disturbances to which the so-called religions offered answers" (2103:59).

In this frame, the strong material component is more and more preponderant. All this, however, has increased the need to draw on an immaterial dimension. In part, this need has been intercepted and incorporated by capitalism itself which, above all, with marketing, has understood how to recover a sort of reference to the immaterial (Baudrillard, 1976), in order to respond apparently to the "spiritual" needs of individuals, but transforming them into something else, more in line with its own project. ${ }^{36}$

35 Past and future are swallowed up in an eternal present celebrated as the only time existing: the perception of continuity, that is of the dynamic and processual nature of time, breaks down. As argued by Hervieu-Léger, in contemporary society we observe a situation brought about by the pure and simple disappearance of every memory that is not immediate and functional (1993).

36 As stated by Boltanski and Chiapello (1999), what distinguishes capitalism is its ability to intercept the reactions towards it by transforming them so as to be able to incorporate 
Beyond consumption, the thrusts in the direction of the immaterial are channeled into other orientations, such as the myth of the "return to origins" which animates some of today's ecological movements, or the logic of giving and sharing proposed in various forms in contemporary societies, especially through the use of Web platforms.

On the more strictly religious front, we may think of the moments of ritual that persist even though they seem out of time in the eyes of contemporary culture. Often considered to be the heart of religiosity, such practices inevitable exposed to the cross pressures that we are discussing-are in danger of losing their specificity, that is their being the possible point of encounter between immanence and transcendence, and of posing, by virtue of this nature, a correspondence between daily life and faith, between an earthly time and an eternal one, between the single person and the community. Different scholars have documented the crisis of such rites and religious practices, reduced to mechanisms emptied of meaning. On closer examination, however, this crisis is actually present but is only one side of the coin. The other side suggests that we investigate more thoroughly, what it means to live religious practice today with all its complement of reference beyond the immanence that envelops daily life, demanding directly to the only person who can speak of such a personal experience: the one who lives it in the first person. ${ }^{37}$

Each of these phenomena of orientation to the immaterial is one of those signs of transcendence and constitutes a laceration of that immanent framework which, according to Taylor, overshadows post-secular society. The complete realization of that framework would lead to what Taylor calls "a purely self-sufficient humanism (...) a humanism accepting no final goals beyond human flourishing, not any allegiance to anything else beyond this flourishing. Of no previous society was this true" (2007:31).

Between immanentistic and disenchanted tendencies, on the one hand, and re-enchantment phenomena on the other, the search for an immaterial dimension (expressed in different ways) and the persistence of the religious phenomenon in its appeal to transcendence contribute to keeping the immanent framework open and not saturated. If this were not so, societies would implode and people would be impoverished of that freedom that arises from distancing themselves from the saturation typical of technical societies, regulated by the logic of functionality: through this distance, individuals are able to access universes of meaning.

them. And, significantly, Pine and Gilmore speak of an "economy of experiences" to underline how also the emotional component is incorporated in the ambits susceptible to entering into the circuit of economic valorisation (2000).

Useful in this direction is the work described in Parts 3, 4, and 5 of this book. 


\section{Conclusive Considerations: Some Issues Related to the Migration} Processes

In this chapter, starting from the literature and from some empirical observations, we have analyzed the secularizing tendencies at work in modernity and contemporaneity, in the light of some effects produced by them within society. More in particular, we focused on "post-secular society" - a society in which the religious experience finds itself in the midst of disenchanting tendencies without, however, definitively succumbing to them. What has changed in it are the conditions of belief and the ways in which we have access to the contents of faith.

We have thus spoken of the emergence of a new demand for subjectivity within the religious experience, which represents a challenge for the religious institutions in their knowing how to place themselves in our time, and simultaneously provokes problematic torsions at the limit of religion itself. We have then focused on the weakening of social bonds, which exposes the individual to new forms of religious aggregation with closed and sometimes radical traits, whilst bringing with itself the need for community inherent in the individual. And we have seen the tendency to adopt a rationalized view of reality that questions the dimension of meaning and conflicts with the religious view in its opening to the transcendence.

The outlook of "post-secular" society suggests that we do not consider such tendencies as a sign indicating an eclipse of religion from social and individual life and, consequently, its possible return after a period of absence: the real circumstance, the starting point for the present reflection about secularization, suggests considering that secularization and religious experience, in other terms modernity (or late-modernity) and religion, do not completely exclude one another.

The scenario of European "post-secular societies", that complex set of secularizing pressures and tendencies moving in the opposite direction as well as cross pressures within it affecting religious experience, subjecting it to new challenges whose conclusion is not foregone, constitutes the frame within which immigration takes place and within which Europe itself is challenged. It is challenged also by migrations to overcome the unresolved, ambivalent tension between the techno-economicism of its politics (especially those related to the migration of labor) and its philosophy of rights (among which there is religious freedom) and solidarity embedded in its foundation project. ${ }^{38}$

38 For a useful analysis of the challenge of migration "in a Janus-Faced Europe", and the oscillation of Europe between positions of openness and closure, pluralism and uniformity, see Zanfrini (2019). 
In some respects, the plural scenario of the European post-secular societies is shaped also by the presence of migrants: the believers with a migration background contribute to shaping the variegated religious landscape, and to the reconsideration of questions set aside following the processes of secularization, even if only for the fact that they make the religious phenomenon more "visible" within European societies by placing at the center issues linked to freedom and human rights.

In the final stage, we shall mention two questions emerging in post-secular society, solicited also, though not only, by the presence of migrants. We refer in particular to religious pluralism and the role of religion in the public area. These are nodes around which unsolved questions and ambivalences of globalization and secularization condense, but also complex challenges in the direction of a re-opening of the horizon with respect to a society that wishes to question itself, beyond the mere technical function, on meanings of human coexistence.

\subsection{The Challenge of Religious Pluralism}

Religious pluralism constitutes the proof that the dream -fed by globalizing tendencies- of a world without differences has not come true. All the migrations -closely connected with the phenomenon of globalization- have contributed to profound changes from a cultural and religious point of view. Not, however, in the sense of a fusion that homologates singularities but in the sense of a coexistence of different religious alternatives. In fact, although the nation States have for a long time tried to impose some homogeneity also from a religious point of view, so as to guarantee social cohesion, the international migratory processes have sustained religious pluralism (Saunders et al., 2016). This is particularly true in the case of Europe, where diversity based on religion is one of the most challenging (Zanfrini, 2019).

If we wished to find a point of contact between religious pluralism and the aspirations of globalization, it would concern the deconstruction of dominant value references. From this point of view, religious pluralism lends itself well to a society where the individual dimension is increasingly preponderant over the collective dimension. Although every religion always tries to meet a need for belonging, the plurality of alternatives has been interpreted as a way to satisfy the need of individuals, especially of the contemporary individuals, to choose - Berger defines this need as "heretical imperative" (Berger, 1979) - and to shape with one's own hands one's personal spiritual and religious path. In this regard, often pluralism is simply confused with a veritable "do-it-yourself religion" (Lucà Trombetta, 2004) put together by the individual who draws on different religious options: it runs the risk of ambiguity, overlapping with relativism. 
In the framework of European religious pluralism, migrants themselves can undergo the influences of the tendencies of individualism and subjectivism. One's religious orientation -which in the case of migrants is often decisive in defining personal and social identities- can therefore weaken, or radicalize by reaction, or can be renegotiated with the context and take on a new form.

On the front of the processes of secularization, religious pluralism produces two effects. On the one hand it belies the "classical" hypotheses of secularization whereby the religious phenomenon, reacting to changes in modernity and in the globalizing dynamics, would simply wither away - or, in the more normative theses would have to wither away. On the other hand, pluralism constitutes a challenge for the more traditional kinds of religion and for the characteristics presented by such religions: the integrity and solidity given by the internal consistency and by the constancy of individual paths; the presence of a strong collective and community dimension, and of dogmas and doctrines stable over time, of a univocal truth bringing salvation, and a consolidated ritual dimension. Also in this case there emerges an underlying ambiguity of religious pluralism, which on the one hand nourishes the religious impulses, but on the other undermines the more traditional forms. This ambiguity cannot be resolved on a theoretical level but must be observed in the concrete of the experiences of individuals and groups. Undoubtedly, some European contexts form an interesting framework for analyzing these processes, because they are contexts with the strong presence of a historical religion (Christianity) in its most evident institutional form. At the same time, they are challenged to rediscover more deeply the contents of their faith, which often contemplates, already in itself, a dimension of opening and plural encounter. This, for historical events (not least the difficulty precisely in facing modernity) and for contingent needs, has been put in the background with the danger, moreover, of weakening the potentialities inherent to religion itself. Pluralism therefore also constitutes a chance where it becomes a reason for a deeper knowledge of its own religious contents. ${ }^{39}$

In addition to the more traditional religions, it is important to acknowledge the presence of other religions, such as the oriental ones -Buddhism and Hinduism-, New Age and the New Religious movements. These, too, reflect the role of migrations and, although their diffusion varies from country to country, their presence is evident also because of media support - an example is the renowned achieved by the Soka Gakkai or by Scientology in the media sphere.

39 Significant in this sense is the Synodal process experienced in the Diocese of Milan: it has contributed to the deeper understanding by believers (both native and immigrants) of the content of their faith (see again Chapter 16). 
These religions are different from the traditional western ones and can often be translated into forms of alternative spirituality rather than true paths of faith - in some cases, in the concrete of the experience of the single individuals, they can be reduced to simple practices or philosophies of life. In this sense, they are difficult to perceive as a menace for Europeans, who on the contrary are curious about these currents running through the pluralism of the western world.

In considering the possible configurations of the relations between Europeans and migrants, it therefore becomes necessary to specify first of all what types of religion enter into relation with one another through people. In addition, the "Christian" population is in reality very varied internally, as an effect of the dynamics above outlined which shape multiple paths: there are those who feel they simply belong to a cultural form; those who adhere for personal belief; those who declare themselves to be convinced Christians but practice intermittently; those who say they are Christian in their own way and adhere to Christianity selectively. ${ }^{40}$

And if, on the one hand, Europeans consider the increase in religious pluralism as a source of cultural enrichment, on the other hand pluralism is interpreted as a cause of conflict if not as even a threat to the identity, especially in relation to Islam - a religion which, though limited in percentage terms, has seen a growing diffusion as a result of migratory flows. The level of mistrust has increased following terrorist attacks in Europe. However, on a different level, the difficulties in reconciling radically different worldviews and ways of thinking of individual and social life often reach public debate: the possibility of building mosques, whether or not to remove the crucifix from state schools, the use of the veil are some such examples. In these debates, religion differently from expectations - enters significantly into the public scene. And the public sphere takes on a crucial role in shaping the integration processes of migrants; it can direct the interpretations but above all the states of mind towards immigrants, just as it can decide to throw light on some phenomena and leave others in the shadow - for example, the fact that in the European territory there are integrated second generations of immigrants, just as there are native Europeans who have converted to Islam.

In the plural religious framework, the encounter and/or the confrontation occur within a context that, in the wake of disenchantment and rationalization,

40 See, for example, for the case of Italy and Catholicism, the research on young generations realized by Bichi and Bignardi (2015); and with reference to migrations (with a high Christian and Catholic internal component) and, more in particular, to the second generation, see Bichi et al. (2018). 
has accentuated some aspects of collective life, at the expense of other dimensions. And, in this context, religion can acquire a crucial position because it is not equivalent to functional and technocratic views of reality but raises questions of meaning regarding social life and the human condition.

\subsection{Religions as "Anti-environments"}

J. Habermas, in his extensive research into the public sphere, has come to identify precisely in religion the models of language and meaning that allow us to name experiences, relationships, history, the world, and hence interpret what otherwise would probably remain unexpressed.

This leads us to the point on the role of religion in the public sphere, which calls into question, more broadly, the meaning of "laïcite", on the one hand, and the task of religion in general, on the other.

As far as "laïcité" is concerned, the French Revolution has bequeathed to us the notion of laïcité to be understood as that condition in which non-religious thought finds its place and legitimacy in a world dominated by the stance defined by the institutionalized Church. From here, given the formation of the State according to the idea of laïcité, what takes shape is the effort to retain the influence of religion within well-defined borders, by relegating it to the private space. However, the question arises whether, in a social world organized around the global technical system and surrounded by an "a purely selfsufficient humanism", where the human dimension of social life is marginalized, it is the right time to review the conception of laïcité, as it often ends in "laicism".

The French philosopher Henri Bergson focused on the ways in which religion, precisely because it is embodied in historical processes, experiences the internal dialectic between openness and closure, between conservation and prophecy. This dialectic, while continuously threatening to render religion organic with the status quo, also enables the continuous evocation of new energies for critical and creative innovation.

In such a direction, religion represents one of the few experiences able to oppose the "purely self-sufficient humanism" that is deeply embedded in our times. A useful idea to capture the potential role of religion is that of the "anti-environment" - a concept used by McLuhan (1964, 1967), which we adapt here to our subject. Within a social context deeply marked by the pervasiveness of rationalization and disenchantment, combined with technical systems constituting the "environment" of our whole individual and social life, "antienvironments" are worth a lot, as they shape a space able to activate some antidotes to the technocratic, homologating colonization of human life. Religion could be one of these "anti-environments"; others are certainly conceivable (i.e. education, arts, etc.). 
By reopening the question of meaning in relation to existence together with the meanings and forms of the human condition, this "anti-environment" is extremely relevant for the freedom of everyone, believers and non-believers. In a world that threatens to collapse on itself, in which technique has no counterweights and reality is confused with individualized points of view, this environment is a valuable bulwark of freedom precisely in redesigning the reference to "transcendence" - a term which describes not only the human openness to a God, a divine otherness, but also a domain of awareness, of openness to the mystery of the other or of creative principles that humans can access in order to receive guidance in relation to sense-making. Transcendence allows us to distance ourselves from historical configurations that are built on an "a purely self-sufficient humanism" pestered by the expansion of technocracy. That idea about transcendence can play a crucial role in stimulating profound processes of social transformation. In such a frame, religion could be considered as a "sacred space of the infinite", as it is able to safeguard human openness to the unexpected and the otherness, and to shape humanly-practicable paths, interweaving the material dimension with the sense-making demands, the finite and the infinite (Magatti, Martinelli, 2012).

Therefore, starting from the important recognition of keeping open the question of meaning, which is strongly related to freedom, it is possible to redefine the issue that historically has gone under the name of "laïcite", going beyond the "immanent frame" which shaped -as Taylor highlights- the social imaginary that arose during the Enlightenment, as people started trying to conceptualize society in self-subsistent terms, which is to say in a way that does not presuppose the existence of a transcendent spiritual reality and does not admit the human possibility to be resilient to defined social patterns.

The assertion of secularization, according to which religion is only a private matter, denies the fact that all societies -even though in different ways- have questioned themselves about the issue of the infinite. Simply because such a question -whatever the answer- concerns the human condition. Of course, this opens up important questions regarding the public sphere and its reorganization. The history of modernity bequeaths to us the awareness that no religion (as well as no ideology, culture or tradition) can reasonably expect to exhaust the universal breadth of human experience. And yet, this does not mean that it is not worth taking into account the great religious traditions as worthy spaces for building a richer social world and, therefore, one more suitable for human condition. The recognition of the collective value of the "sacred space of the infinite", for example, may create a more favorable condition for the development of the intercultural and interreligious dialogue that is a current human imperative of our time and that may be deployed not only horizontally among different conceptions of values- but also vertically, namely by 
considering the structural openness of the human being to transcendence as an unavoidable feature. It is an openness to which every culture and religion offers answers and different realizations.

This "sacred space of the infinite" includes the religious dimension within the public life not as a compensatory receptacle of those problematic consequences of socio-economic development models that succeed over time. If it were such a receptacle (as it often is), it would be unable to distance itself from the principles of those models. Rather, the "sacred space of the infinite" precisely through a new understanding of "laicite" - becomes a valuable "antienvironment" that allows us to always reopen the issue of sense about collective living and the plurality of human achievements. Its potentiality comes into play both in challenging dogmatisms that even in a free society eventually rise, and in fighting fundamentalism of religions that becomes more likely the higher the demand for meaning raised by religion is censored.

In conclusion, post-secular society expresses the emergence of a new epoch in relation to the epoch of secularization, a time in which the religious phenomenon is affected by profound changes and does not at all seem doomed to disappear. The challenge is rather to recognize, on the one hand, the new risks punctuating the religious experience and, on the other, to capture the signals, often formless and not yet institutionalized, that open up in post-secular societies, by going in the direction of considering religion - understood as a possible "anti-environment" and a "sacred space of the infinite" - as a sphere that can safeguard dimensions of the human (opening towards transcendence, the central role of meanings, the uniqueness and dignity of the person, the cruciality of bonds and the recognition of the other, the importance of questions such as justice, peace, the safeguard of creation, etc.) which make up a heritage of value for all. 